\title{
Destroying your immune system
}

\section{Commentary}

A friend of ours, really the husband of a friend, has cancer. Yes, horrible and we pray for his recovery. He is currently in Scotland as they are bi-continental (is that a word?); living in Scotland and West Virginia, USA. Anyway, he was complaining of 'back pain' from shovelling snow in West Virginia, and then they flew to their other home in Scotland where the pain continued to worsen. He went to the hospital and, long story short, was diagnosed with both lung and bone cancer! Not what you want to hear. So they served him haggis (A Scottish dish consisting of a sheep's or calf's offal mixed with suet, oatmeal, and seasoning and boiled in a bag, traditionally one made from the animal's stomach), not great if you espouse a Plant Based Lifestyle for healing! Next they explained that they would be 'destroying his immune system' so that the chemo drug treatments would work! How is that for counter-intuitive treatment modalities?

\section{Destroy the immune system?}

What are they thinking, or are they? Do they just follow the instruction manual on the poison or do they actually examine what they just told our friend? They are going to obliterate the body's natural ability to defend itself; already compromised because he got cancer in the first place. Well people with Strong Immune systems just don't get sick; whether it's a cold, flue or cancer. Just doesn't happen very often. In fact, there are thousands of US Nutritional Holistic Survivors who have 'beat' cancer by strengthening our natural immune systems to beat cancer and stop it in its tracks! Most people, who are 'treated' for cancer, don't often actually DIE of the disease but they die of 'complications' or other illnesses while being treated for cancer.

\section{Why?}

Their natural immune systems have been destroyed, so they die of pneumonia or other minor ailments that would have naturally been
Volume 6 Issue 2 - 2017

\author{
Skip Stein \\ Plant Based Lifestyle Consultant, Whole Foods 4 Healthy Living, \\ USA
}

Correspondence: Skip Stein, Plant Based Lifestyle Consultant, Chief Operating Officer,Whole Foods 4 Healthy Living, Orlando, USA, Tel 40768368I6, Email SkipStein@newtimers.org

Received: July 31, 2016 | Published: March 20, 2017

fought off by a normal/strong natural immune system. I don't have an answer for anyone but myself. I chose a natural route of a Plant Based Lifestyle, diet and nutrition to fight my prostate cancer. The traditional doctors told me I'd be dead, dead, dead long ago; even with their treatments. Actually I'm healthier NOW at 70 than I ever was at 40 ! Go figure! If YOU or a loved one has cancer (or any other lifestyle disease), I'm not going to advise you about anything. BUT, if you want to improve your chances of living try, just try, a Plant Based Lifestyle, diet and nutritional approach; even while you undergo conventional treatment. It certainly can't hurt and it may just help you recover faster from the devastating treatment protocols. You should always advise your doctor of a serious nutritional change as it could interfere with the drug therapies they administer.

\section{Acknowledgements}

None.

\section{Conflict of interest}

Author declares that there is no conflict of interest. 